\title{
ROSELLE CALYX ETHANOL EXTRACT STIMULATES ORAL MUCOSAL WOUND HEALING
}

\author{
SARWONO AT, SUNIARTI DF*
}

Department of Oral Biology, Faculty of Dentistry, Universitas Indonesia, Jakarta, Indonesia. Email: dewisuniarti@yahoo.com Received: 16 September 2017, Revised and Accepted: 3 October 2017

\begin{abstract}
Objective: This study aim to analyze the effect of the roselle calyx ethanol extract on oral mucosal wound healing.

Methods: Male Sprague Dawley rats (3 month, 150 g) were housed under standard temperature conditions $\left(20-22^{\circ} \mathrm{C}\right)$. Punch biopsy wounds were inflicted on the inferior labial mucosal membrane of rats. All treatments (normal saline; $0.1 \%$ triamcinolone acetonide; and 3.75\%, $7.5 \%$, and $15 \%$ roselle calyx ethanol extract) were applied 2 times daily. Wounded areas were observed after 8 days of treatment. The specimen of the wounded area was prepared and microscopic slides were analyzed under a light microscope.
\end{abstract}

Results: The histological features of the groups treated with TA and 7.5\% roselle calyx ethanol extract showed a similar formation of the epidermis layer and no lymphocytic infiltration of the lamina propria.

Conclusion: The application of $7.5 \%$ roselle calyx ethanol extract could stimulate oral mucosal wound healing.

Keywords: Roselle calyx, Ethanol extract, Triamcinolone acetonide, Wound healing activity, Anti-inflammatory, Oral mucous.

(C) 2017 The Authors. Published by Innovare Academic Sciences Pvt Ltd. This is an open access article under the CC BY license (http://creativecommons. org/licenses/by/4. 0/) DOI: http://dx.doi.org/10.22159/ijap.2017.v9s2.10

\section{INTRODUCTION}

The oral mucosal membrane is prone to developing wounds originating from trauma or immunological processes [1]. Cheek mucosal membranes are frequently wounded, especially as a result of brushing teeth, accidental cheek bites, or occlusal disharmony [2]. Such wounds in the mucosal membrane are called ulcers, or aphthous ulcers, which manifest as painful lesions that range from the size of a pinhead to several centimeters in diameter; these usually cause pain and discomfort during eating and speaking $[2,3]$. The aim of wound care, which must occur in a physiologic environment conducive to tissue repair and regeneration, is to promote healing in the shortest time possible, to prevent secondary infections, and to minimize pain, discomfort, and scarring $[3,4]$. Wound healing is a complex process that involves three main phases: (1) The activation of different types of inflammatory cells or responses, (2) the formulation of granulation tissue as a result of cell proliferation during healing, and (3) the remodeling of tissues [1,5]. The healing process is influenced by several factors such as infection, nutrition, drugs, and hormones; the type, depth, and sites of wounds and certain disease conditions may also impact healing [4]. In addition, remodeling of the dermis requires collagen, antioxidants, and both matrix-producing proteins and protease enzymes, which are essential for initiating the remodeling of tissues during wound recovery [6-8].

Many studies over recent years have focused on finding effective treatments for oral ulcerations. Localized topical regimens are considered standard treatment for mild cases of oral ulcers [4,5,9]. Many indigenous tribes around the world have long used annual herbaceous plants for their wound healing properties, although these have not received the attention of orthodox medical practitioners as potential sources of healing agents that could prove useful in the treatment of wounds or oral mucosal ulcers $[1,3,4]$.

Standard topical treatment options that provide relief from pain and symptoms include analgesics, anesthetics, and antiseptics, as well as the application of antioxidant, antimicrobial, and anti-inflammatory agents, diuretic, laxative, antihypertensive, or antihyperlipidemia [4,9-12], anti-obesity, hypotensive, antidiabetic, immunomodulatory, hypocholesterolemic, anticancer, hepatoprotective, renoprotective, and antiurolithiatic properties [7,8,11,13]. A number of medicinal plants, such as Jatropha cucas, Morinda citrifolia, Cassia alata, and Hibiscus sabdariffa Linn. (roselle), among others, have been employed in folk medicine for wound care [5]. Many parts of the roselle plant, for instance, are of value, including the leaves, yellow or reddish calyxes, seeds, and fibers. Roselle is associated with traditional medicine in Mexico, Africa, India, and several other Asian countries and is claimed to possess various therapeutic and pharmacological activities [3,4]. In addition, the calyxes are commonly used to brew hot or cold beverage and medicines $[4,5,9,13]$. Although this plant has a long history of use across cultures, the recent scientific validation has augmented its status as a nutrition resource. Food industries have started incorporating their calyces into various products $[10,13]$.

In examining the healing properties of roselle calyxes, different studies have identified their phytochemical content, including their mineral and ash content, color, and odor, in addition to their efficacy as an antibacterial agent for treating periodontal disease in vitro, their safety based on the LD50 value, and their cytotoxicity toward epithelial and fibroblast cells in vitro $[1,3,4]$.

The phytochemical screening of water and alcoholic extracts of the calyxes has shown the presence of biochemicals such as anthocyanins, protocatechuic acid, flavonoids, and saponin. [4,7,8,11]. The calyxes are also rich in ascorbic acid, riboflavin, niacin, copper, zinc, manganese, and iron [4,5,6,9-12]. In particular, saponins are plant extracts endowed with extensive biological activities that promote antioxidant and antiinflammatory reactions $[6,8]$.

The aim of this study was to analyze the effect of roselle calyx ethanol extracts on oral mucosal wound healing in Sprague Dawley (S-D) rats.

\section{METHODS}

Plant extracts prepared

Collected calyxes were separated from undesirable plant parts and materials and were then air-dried for 10 days. After drying, the calyxes 
were ground into a coarse powder with a grinder. The plant powder was stored in an airtight container and kept in a cool and dry place. $100 \mathrm{~g}$ of the dried powder was placed in a sterile glass jar with a plastic cover, and $95 \%$ ethanol (500 $\mathrm{ml}$ ) was poured into the jar. The jar was properly closed to prevent the entry of air. This jar was left to rest for 10 days and shaken several times during the process. After the extraction, clean and white cotton material was used to filter the extract twice. Then, the extract was filtered through Whatman No 14 filter paper. The filtrate was collected in a beaker and evaporated under a ceiling fan to dry. It rendered a gummy concentrate of deep, reddish black color. Finally, the extract was stored at $4^{\circ} \mathrm{C}$ until the following research protocols were ready (Fig. 1) [1,2].

\section{Animal protocol}

Twenty-five adult male Sprague Dawley rats (3 month, 150-200 g body weight) were used in the experiment. The Animal Ethics Committee of the Primate Research Center, Bogor Agricultural Institute, Indonesia approved the protocol. Rats were kept under standard environmental conditions for 1 week in the animal house. The rats were housed in plastic cages with pine sawdust covered floors at a temperature of 24$25^{\circ} \mathrm{C}$ under a light-dark cycle of $12 \mathrm{~h}$ and were fed ad libitum a standard pellet diet. All experiments were conducted in isolated and noiseless conditions. The animals were randomly distributed into 8 cages with 6 animals each and were identified and weighed daily. The date of sacrifice was recorded for each rat [2,3].

\section{Experimental protocol}

Animals were randomly separated into two groups and were anesthetized with $10 \%$ chloral hydrate $(30 \mathrm{ml} / 0.1 \mathrm{~g})$ through intraperitoneal injection. The animals were observed during the post-operative period until their total recovery of reflexes. After the anesthetic stage was reached, each animal was placed on a surgical table in dorsal decubitus position and immobilized with adhesive tape. The mucosal membrane was sterilized using a swab covered in $0.12 \%$ chlorhexidine digluconate. The ulceration was made in the inferior labial mucosal membrane using a No. 15 scalpel blade. To standardize the wound area, a 4-mm diameter demarcate was used.

The operation technique was standardized for all animals and was performed by the same operator. To control the results, variations in body weight and temperature were observed. The Group I animals were treated with normal saline as a negative control and $0.1 \%$ triamcinolone acetonide in the dental paste as a positive control. The Group II animals were treated with either $3.75 \%, 7.5 \%$, or $15 \%$ roselle calyx ethanol extract. All treatments were applied twice a day, in the morning and the afternoon, for 7 days. Before treatment, the wound diameter, body weight, body temperature, and behavior of all animals were monitored.

\section{Histological analysis}

On days 8 after treatment, all animals were sacrificed, and wound areas were measured using a caliper. The tissues around wounded areas were dissected and fixed in neutral buffered formalin for $24 \mathrm{~h}$. After fixation, the specimens were microscopically analysis and prepared for microscopic analysis: Specimens were subjected to dehydration in crescent alcoholic series, deemphasized in xylol, impregnated with paraffin, and melted at $60^{\circ} \mathrm{C}$. Then, the fragments were placed in paraffin forming blocks at room temperature.

The fragments were sectioned at $5 \mu \mathrm{m}$ thicknesses with a microtome, and histology was performed according to both the routine staining procedure using hematoxylin-eosin (HE) and the specialized Trichrome Masson's staining protocol. Analyses of blinded and calibrated specimens were performed under an optical microscope by two pathologists in the Pathology Laboratory of the Primate Research Center, Bogor Agricultural Institute.

\section{RESULTS}

Wound diameters before treatment and at day 8 after treatment are shown in Fig. 2. The wound diameters of Group I rats treated with the normal saline solution differed significantly from those treated with TA $(\mathrm{p}<0.05)$. The wound diameters of Group II rats treated with $3.75 \%$, $7.5 \%$, and $15 \%$ roselle calyx ethanol extracts also differed significantly $(\mathrm{p}<0.05)$.

Treatments with $7.5 \%$ roselle calyx ethanol extracts and with TA resulted in nearly similar wound diameters at day 8 . Treatment with $3.75 \%$ roselle calyx ethanol extract resulted in wound diameter, similar near those of the saline treatment, yet the $15 \%$ roselle calyx ethanol extract performed better and reduced wound diameter to a greater extent.

The histological study of HE stained tissues showed that the wound edges of the group treated with $7.5 \%$ roselle calyx ethanol extract were covered by epithelium, more rete ridges, and fewer keratin layers and showed reduced capillary vasodilatation, similar to the TA treatment group shown in Fig. 3a and c. Meanwhile, the wound edges of the group treated with $15 \%$ roselle calyx ethanol extract were covered by less complete epithelium and showed the infiltration of chronic inflammatory cells up to the epithelium are shown in Fig. $3 \mathrm{~d}$. In the groups treated with $3.75 \%$ roselle calyx ethanol extract and with saline, open wounds and greater infiltration of inflammatory cells up to the epithelial area were observed shown in Fig. $3 \mathrm{~b}$ and e.

The histological study using Masson's trichrome staining protocol showed collagen deposits as pink in color. The appearance of the tissue treated with $7.5 \%$ roselle calyx ethanol extract, which is covered by epithelium and moderate collagen deposits, is similar to the tissue treated by TA shown in Fig. 4a and c. The tissue treated with 15\% roselle calyx ethanol extract is covered by a less complete epithelium and collagen deposits shown in Fig. 4d. Finally, tissues treated with $3.75 \%$ roselle calyx ethanol extract and with saline still displayed open wounds and infiltration of inflammatory cells up to the epithelial area in Fig. 4a and e.

\section{DISCUSSION}

In studies involving oral mucosal membranes, rats are commonly used because they present some advantages in relation to other animals. Several advantages include the low cost of their maintenance and specialized diets as well as their easy manipulation and maintenance in controlled environmental and sanitary conditions $[3,6,12,13]$. Another advantage is the similarity between the oral mucosal membranes of rats and humans, which are basically made up of epithelial tissues on the surface and subjacent connective tissue called the basal lamina that provide support and nutrition to the epithelium. Traumatic wounds are the most common inflammatory conditions in the oral cavity, and cheek mucosa is the most frequently traumatized tissue $[1,3]$

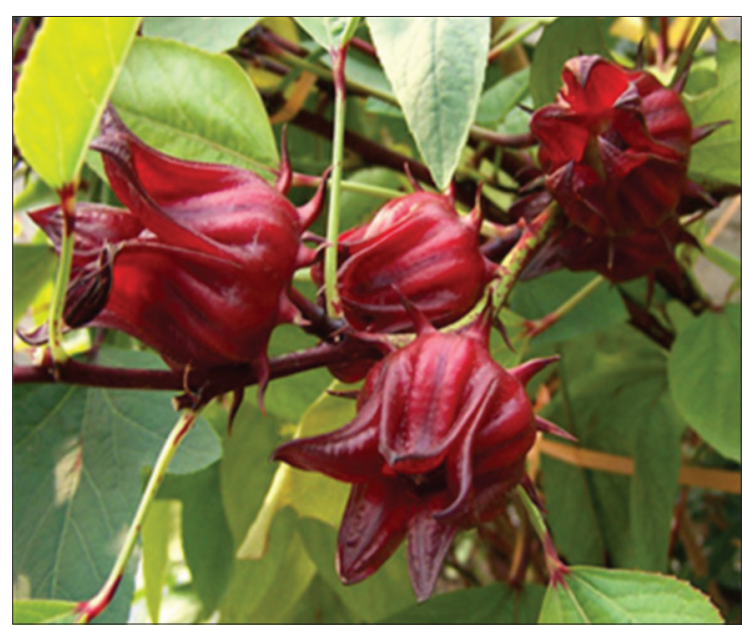

Fig. 1: Roselle calyxes 


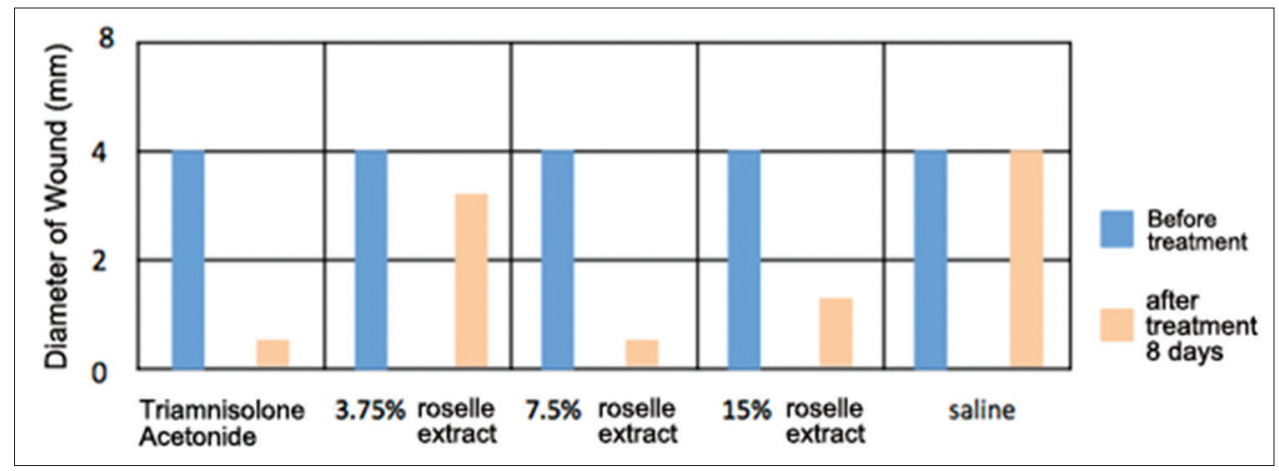

Fig. 2: Diameter wounds before and after treatment

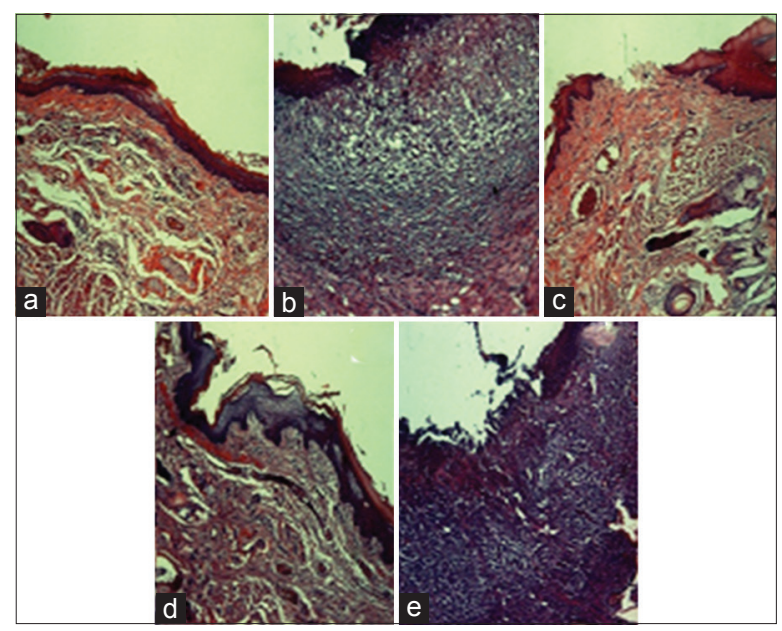

Fig. 3: Hematoxylin-eosin staining: (a) Triamcinolone acetonide, (b) $3.75 \%$ roselle, (c) $7.5 \%$ roselle, (d) $15 \%$ roselle, (e) saline, $\times 400$

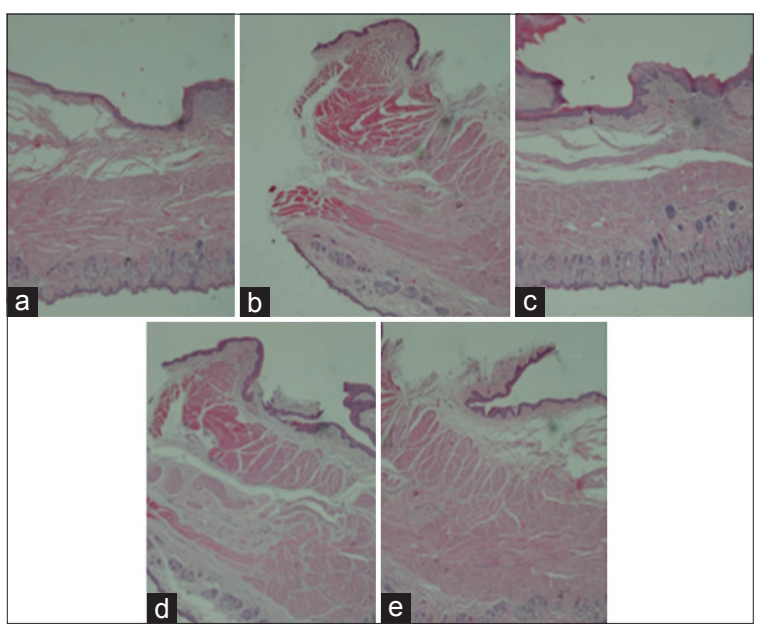

Fig. 4: Trichrome Masson's staining: (a) Triamcinolone acetonide, (b) $3.75 \%$ roselle, (c) $7.5 \%$ roselle, (d) $15 \%$ roselle, (e) saline, $\times 400$

often as a result of brushing teeth, accidental cheek bites, or occlusal disharmony $[2,4,6]$.

H. sabdariffa Linn shown in Fig. 1 commonly known as roselle, is a species of the Malvaceae family with red calyxes [8,10], although it has different local names in several countries. In Saudi Arabia, Nigeria, Egypt, and Sudan, this species is called karkade $[8,14]$. In Australia and India, it is called roselle or red sorrel. Meanwhile, it is called chin baung in the Indian subcontinent, krajeab in Myanmar, zobo in Thailand, and merambos ijo in Indonesia [3,5,12]. Many parts of the plant have reported medicinal value. Former studies have evaluated the use of this plant and its parts or extracts in treatments for several diseases, such as hypertension, as well as in treatments for skin wounds, diarrhea, and urinary tract infections $[4,5,8,9]$.

The juice from its calyxes is claimed to be a health-enhancing drink because of its high contain of Vitamin C, anthocyanins $[4,7,8,10,13]$, and protocatechuic acid [4]. Another former study reported that as an antioxidant, roselle has low bioavailability due to high acidity. Development of chitosan nanoparticle from roselle extract was expected to improve the bioavailability and the acidity problem [7].

The dried calyxes contain flavonoids, including gossypetin, hibiscetine, and sabdaretin [6,9]. Wound healing is a coordinated process that involves inflammatory cells, cell proliferation, collagen synthesis, and scar formation. Various therapies are currently used for treating open and chronic wounds. To generate new tissue and heal wounds, fibroblasts proliferate to increase cell numbers and also to produce several extracellular matrix proteins and growth factors $[3,4,6]$.

In this study, clinical examination of 4-mm mucosal wounds, surrounded by swelling and hyperemic areas, on the inferior labial mucosal membranes of rats were performed following several treatments. On the $3^{\text {rd }}$ day after ulcer induction, feeding was impaired, and rats became unfriendly. By the $5^{\text {th }}$ day, as cicatrization proceeded, the feeding process was reestablished and consequently made the rats friendlier [10]. This result is supported by former studies that found that healing of ulcers leads to increased body weight $[2,5,6]$.

Our study showed a progression in wound healing after the applied treatments shown in Fig. 2. The histopathology study of HE-stained tissues is in Fig. 3. Shown that the wound edges of rats treated with $7.5 \%$ roselle calyx ethanol extracts were covered by epithelium, more rete ridges, and fewer keratin layers and showed reduced capillary vasodilatation, similar to the TA-treated group shown in Fig. $3 \mathrm{a}$ and c. The wound edges of rats treated with the $15 \%$ roselle calyx ethanol extract were covered by less complete epithelium and showed infiltration of chronic inflammatory cells up to epithelium area. Finally, the rats treated with the $3.75 \%$ roselle calyx group ethanol extract had open wounds and greater infiltration of inflammatory cells up to the epithelial area, similar to the group treated with saline.

The prior study reported that liver of Swiss male mice treated with karkade showed few histologic changes against normal liver, increased mitotic division, increase in Kupffer cells with normal-looking tissue; while aqueous extracts of karkade showed less hemorrhage, vacillation, and inflammation; and that might be due to decreasing oxidative stress and reducing cell death. The act of aqueous extract karkade in stimulating cellular repair due to it contains anthocyanins and flavonoids, which has effective antioxidant and protects the body from free radical and stimulate the inflammatory response [14]. 
Another prior study of a crude aqueous extract of $H$. sabdariffa on the colon of Wistar rats showed a significant increase in the level of goblet cells and mucin secretions in the colon mucosa. This report provided further evidence that the medicinal components of $H$. sabdariffa extract have a potential effect on an anti-inflammatory activity in the colon $[3,14]$.

The histological study of Trichrome Masson's stained tissue sections shown in Fig. 4 with collagen deposits as pink in color. The tissues treated with $7.5 \%$ roselle calyx ethanol extract, which was covered by epithelium and moderate collagen deposits, were similar to those of the TA treatment group shown in Fig. $4 \mathrm{a}$ and c. Meanwhile, the tissues treated with 15\% roselle calyx ethanol extract were covered to a lesser extent by epithelium and collagen deposits. The tissues treated with the $3.75 \%$ roselle calyx ethanol extract and normal saline had open wounds and indicated the infiltration of inflammatory cells up to the epithelial area.

The ulcerations made by a No.15 scalpel blade labial mucosal membranes thus resulted in an acute inflammatory response. Even so, treatment with roselle calyx ethanol extract appeared to reduce the diameter of wounds shown in Fig. 2 and encourage the healing process shown in Figs. 3 and 4 . This is likely due to the anti-inflammatory activity of roselle calyxes. This research was support by many former studies that reported that roselle calyxes consist of flavonoids such as gossypetin, hibiscetine, and sabdaretin, and are also good sources of lipid-soluble antioxidants [6] and gamma tocopherols [15]. Direct evidence supports the anti-inflammatory efficacy of roselle and its capacity to reduce vasodilatation and to improve edematous conditions, thereby reducing inflammation [2-4,6].

Previous studies have reported that the calyx extract of roselle possesses significant anti-inflammatory activities, which are supported by its applications in traditional medicine $[1,4,8,9,16-18]$ in addition to antimicrobial activity against Escherichia coli $[8,16,18]$, Staphylococcus aureus, Streptococcus pyogenes, Pseudomonas aeruginosa, Klebsiella pneumoniae, and Proteus mirabilis [18]. The phytochemical, pharmacological, and toxicological properties of roselle are related to the steroids, alkaloids, saponins, flavonoids, tannins $[3,11,12,15]$, and polyuronides contained in this plant [8]. Previous studies reported that saponin extracted from ginseng, for example, accelerates neovascularization in burn wounds on the skin of mice through a reduction in neutrophil entry to wounds, therefore lessening chronic inflammatory reactions $[4,6,10]$.

Prior studies have reported that the rate of tissue repair recovers after the first 3 post-surgical days once the acute inflammatory process has reached its peak $[4,10,13]$. In this phase, a change in histological features could also be observed, including the presence of mononuclear cell infiltrate, mainly lymphocytes, and macrophages. In this stage, macrophages increase their metabolism on activation and begin to release products that act as intermediaries of the inflammatory process $[4,7,10,13]$. However, some animals can still show persistent inflammation resulting from secondary infection by other oral bacteria following surgical injury, which slows the repair process of labial mucosa $[3,6,15]$.

In this study, HE and Trichrome Masson staining showed the bundle formation of cell fibroblast. This study is supported by former study that reported a bundle formation of fibroblast and abundant granulation tissue is characteristic of chronic inflammation that grows from the border of a wound in a centripetal pattern. This process is performed by activating fibroblast that has similar properties to smooth muscle cells, enabling necessary contraction and tension for damage repair. Growth factors are of great importance in the migration, proliferation, and differentiation of epithelial cells as well as in the formation of connective tissue and the growth of new vessels during the healing process $[2,16,19]$.

Former studies also reported that surgical wounds developed keloid tissue (collagen scarring) or led to extended coagulation necrosis in all tissue layers of the oral cavity $[6,14,19]$. Former in vitro study reported that roselle extract showed the novel property as potential supplement and gene protectant against oxidative damage to culture hematopoietic stem cells. It was determined that, in short-term culture, the addition of roselle extract at specific concentration could increase the number of murine bone marrow cell and hematopoietic stem/progenitor cells respond to exogenous agents on proliferation, and that roselle antioxidant flavonoids could restore their intracellular antioxidant system [20].

\section{CONCLUSION}

The application of $7.5 \%$ roselle calyx ethanol extract was found to stimulate the healing of oral mucosal wounds in S-D rats.

\section{ACKNOWLEDGMENTS}

We would like to thank the Primate Research Center of the Bogor Agricultural Institute and the Pharmacology Department of the University of Indonesia. This work was supported by 2013-2015 BIPA grants. The author thanks Ms. Lis Rosmanah for her helpful comments on the manuscript.

Publication of this manuscript is supported by Universitas Indonesia.

This research was approved by the Ethical Committee, Faculty of Dentistry Universitas Indonesia, in Number: 53/ethical clearance/FKGUI/VII/2013.

\section{REFERENCES}

1. Jettanacheawchankit S, Sasithanasate S, Sangvanich P, Banlunara W, Thunyakitpisal P. Acemannan stimulates gingival fibroblast proliferation: Expression of keratinocyte growth factor-1, vascular endothelial growth factor, and Type 1 collagen; and wound healing. J Pharmacol Sci 2009; 109:525-31.

2. Jain SJ, Jain N, Tiwari A, Balekar N, Jain DK. Simple evaluation of wound healing activity of polyhedral formulation of roots of Ageratum conyzoides Linn. Asian J Res Chem 2009;2:135-8.

3. Erhunmwunse MO, Odiase DE. Histological effects of chronic adminstration of crude aqueous extract of Hibiscus sabdariffa on the colon of Wistar rats. Int J Adv Pharm Sci Technol 2014;2:21-6.

4. Builders PF, Kabele-Toge B, Builders M, Chindo BA, Anwunobi PA, Isimi YC. Wound healing potential of formulated extract from hibiscus sabdariffa calyx. Indian J Pharm Sci 2013;75:45-52.

5. Sarr M, Ngom S, Kane MO, Wele A, Diop D, Sarr B, et al. In vitro vasorelaxation mechanisms of bioactive compounds extracted from Hibiscus sabdariffa on rat thoracic aorta. Nutr Metab (Lond)2009;6:45.

6. Kim YS, Cho IH, Jeong MJ, Jeong SJ, Nah SY, Cho YS, et al. Therapeutic effect of total ginseng saponin on skin wound healing. J Ginseng Res 2011;35:360-7.

7. Nurkhasanah, Yuwono T, Nurani LH, Rizki MI, Kraisintu K. The development of chitosannanoparticles from Hibiscus sabdariffa L-calyx extract from Indonesia and Thailand. Int $\mathrm{J}$ Pham Sci Res 2015;6:1855-61.

8. Eltayeib AA, Hamade H. Phytochemical and chemical composition of water extract of Hibiscus sabdariffa (Red karkade calyces) in North Kordofan Sate-Sudan. Int J Adv Res Chem Sci 2014;1:10-3

9. Alqasoumi S, Al-Dosari M, Al-Sohaibani M, Al-Howiriny T, Al-Yahya M, Rafatullah S. Gastric ulcer protective activity of Hibiscus sabdariffa: An experimental, biochemical and histology study. Clin Exp Med J 2010;4:115-27.

10. Patel S. Hibiscus sabdariffa: An ideal yet under-exploited candidate for nutraceutical applications. Biomed Prev Nutr 2014;4:23-7.

11. Ochani PC, D'Mello P. Antioxidant and antihyperlipidemic activity of Hibiscus sabdariffa Linn. leaves and calyces extracts in rats. Indian J Exp Biol 2009; 47:276-82.

12. Gosain S, Ircchiaya R, Sharma PC, Thareja S, Kalra A, Deep A, et al. Hypolipidemic effect of ethanolic extract from leaves of Hibiscus sabdariffa Linn in hyperlipidemic rats. Acta Pol Pharm 2010;67:179-84.

13. Cid-Ortega S, Guerrero-Beltran JA. Roselle calyces (Hibiscus sabdariffa), an alternative to the food and beverages indsutries: A review. J Food Sci Technol 2015;52:6859-69.

14. Al-Budairy A, Fadil N, Al-Ameer MA. Histological study of effect of thyroxin and aqueous extract of karkade on liver in Swiss male mice. 
Mag Al-Kufa Univ Biol 2011;3:201-9.

15. Mohamed R, Fernández J, Pineda M, Aguilar M. Roselle (Hibiscus sabdariffa) seed oil is a rich source of gamma-tocopherol. J Food Sci 2007;72:S207-11.

16. Sukhitashvili N, Imnadze I, Tabaghua G, Gogilashvili Q, Amiranashvili I. Characterization of oral ulcer and pathological scar in nude mice model. Georgian Med News 2012;205:82-7.

17. Ali MK, Ashraf A, Biswas NN, Karmakar UK, Afroz S. Antinociceptive, anti-inflammatory and antidiarrheal activities of ethanolic calyx extract of Hibiscus sabdariffa Linn. (Malvaceae) in mice. Zhong Xi Yi Jie He Xue Bao 2011;9:626-31.
18. Begashaw B, Mishra B, Tsegaw A, Shewamene Z. Methanol leaves extract Hibiscus micranthus Linn exhibited antibacterial and wound healing activities. BMC Complement Altern Med 2017;17:337.

19. Fullerton M, Khatiwada J, Johnson JU, Davis S, Williams LE. Determination of antimicrobial activity of sorrel (Hibiscus sabdariffa) on Escherichia coli $\mathrm{O} 157: \mathrm{H} 7$ isolated from food, veterinary, and clinical samples. J Med Food 2011;14:950-6.

20. Abdul Hamid Z, Lin Lin WH, Abdalla BJ, Bee Yuen O, Latif ES, Mohamed J, et al. The role of Hibiscus sabdariffa L. (Roselle) in maintenance of ex vivo murine bone marrow-derived hematopoietic stem cells. Sci World J 2014;2014:258192. 